\title{
Lipídeos séricos e morfologia hepática de ratos alimentados com diferentes fontes lipídicas (óleo de soja, gordura de peixe e porco, margarina e manteiga $)^{1}$
}

\author{
Serum lipids and hepatic morphology of rats fed \\ different lipid sources (soybean oil, fish \\ fat and lard, margarine and butter)
}

Martha Elisa Ferreira de ALMEIDA²

José Humberto de QUEIROZ ${ }^{3}$

Neuza Maria Brunoro COSTA ${ }^{4}$

Sérgio Luis Pinto MATTA ${ }^{5}$

RES U M O

\section{Objetivo}

Analisar as alterações lipídicas séricas e morfológicas hepáticas de ratos alimentados com diferentes fontes lipídicas (óleo de soja, gordura de peixe e porco, margarina e manteiga).

\section{Métodos}

Os 50 ratos Wistars utilizados no estudo foram divididos em cinco grupos, que durante 28 dias receberam dietas semissintéticas com diferentes fontes lipídicas: óleo de soja, gordura de porco, manteiga, margarina e gordura de peixe. Foram avaliados os pesos corporais, o consumo alimentar e o coeficiente de eficiência alimentar; a atividade da lipase lipoproteica; as concentrações séricas de colesterol total e de lipoproteína de alta densidade - colesterol, triacilgliceróis e albumina, bem como a histologia dos tecidos hepático e cardíaco.

\section{Resultados}

O tipo de fonte lipídica não influenciou o consumo alimentar, o ganho de peso, o coeficiente de eficiência alimentar dos animais, nem a atividade da lipase lipoproteica, porém promoveu alterações nas concentrações

\footnotetext{
$\overline{1}$ Artigo elaborado a partir da dissertação de M.E.F. ALMEIDA, intitulada "Perfil lipídico e morfologia hepática, aórtica e cardíaca de ratos alimentados com diferentes fontes lipídicas". Universidade Federal de Viçosa; 2003. Apoio: Coordenação de Aperfeiçoamento de Pessoal de Nível Superior.

2 Universidade Federal de Viçosa, Instituto de Ciências Biológicas e da Saúde. Campus de Rio Paranaíba, Caixa Postal 22, 38810-000, Rio Paranaíba, MG, Brasil. Correspondência para/Correspondence to: M.E.F. ALMEIDA. E-mail: <martha.almeida@ufv.br>.

${ }^{3}$ Universidade Federal de Viçosa, Departamento de Bioquímica. Viçosa, MG, Brasil.

${ }^{4}$ Universidade Federal de Viçosa, Departamento de Nutrição e Saúde. Viçosa, MG, Brasil.

5 Universidade Federal de Viçosa, Departamento de Biologia. Viçosa, MG, Brasil.
} 
144 | M.E.F. ALMEIDA et al.

séricas de colesterol total, lipoproteína de alta densidade - colesterol, triacilgliceróis e albumina. Todos os grupos apresentaram gotículas lipídicas nas paredes coronarianas e nos capilares cardíacos, sendo caracterizada como esteatose a deposição de gordura no fígado dos animais que receberam óleo de soja, gordura de peixe, de porco e manteiga.

\section{Conclusão}

A fonte lipídica que apresentou os melhores resultados foi o óleo de soja, enquanto o consumo de gordura do peixe causou efeito sérico e tecidual semelhante ao encontrado para as outras fontes lipídicas (gordura de porco, manteiga e margarina), as quais podem contribuir para o surgimento e a progressão das doenças cardiovasculares.

Termos de indexação: Ácidos graxos. Histologia. Lipídeos. Rato.

\section{A B S T R A C T}

\section{Objective}

This study analyzed serum lipids and hepatics morphological changes in rats fed different lipid sources (soybean oil, fish fat and lard, margarine and butter).

\section{Methods}

Fifty Wistar rats were divided into five groups. They were given semi-synthetic diets with different lipid sources for 28 days: soybean oil, lard, butter, margarine and fish fat. Body weight, food intake, food efficiency coefficient, lipoprotein lipase activity, serum concentrations of total cholesterol and high density lipoprotein-cholesterol, triacylglycerols and albumin were assessed. The heart and liver tissues underwent histological assessment.

\section{Results}

The type of lipid source did not influence food intake, weight gain or food efficiency coefficient. The activity of the lipoprotein lipase was also unaffected; however, there were changes in the serum concentration of total cholesterol, high density lipoprotein-cholesterol, triacylglycerols and albumin. All groups presented lipid droplets on the coronary walls and heart capillaries. The fat deposition on the liver of animals given soybean oil, fish fat and lard, and butter was characterized as steatosis.

\section{Conclusion}

The lipid source that presented the best results was soybean oil. Fish fat affected the serum and tissues similarly to other lipid sources (lard, butter and margarine). This may contribute to the onset and progression of cardiovascular diseases.

Indexing terms: Fatty acids. Histology. Lipids. Rat.

\section{N T R O D U ÇÃ O}

Na década de 1950 foi observado que o consumo dos óleos de milho e peixe, e de alimentos ricos em ácidos graxos poli-insaturados promovia a redução da colesterolemia em pacientes com aterosclerose ${ }^{1}$. Desde então surgiu um grande interesse pelo consumo de fontes alimentares ricas em ácidos graxos poli-insaturados, como óleos vegetais e peixes de águas frias e profundas ${ }^{2}$. Entretanto, grande parte dos peixes consumidos no Brasil são de água doce e apresentam-se ricos em gorduras, com elevada concentração de ácidos graxos saturados com poder hipercolesterolemiante ${ }^{3}$.
Mudanças nos padrões alimentares vêm sendo observadas desde as décadas de 1970 e 1980, principalmente quanto ao consumo das gorduras, em que se tem evidenciado um substancial aumento da ingestão dos alimentos de origem vegetal, em detrimento daqueles de origem animal. Ocorreram várias substituições alimentares, dentre as quais a gordura de porco pelos óleos vegetais, e a manteiga pela margarina. Essas mudanças foram propiciadas pela disponibilidade aumentada dos produtos de origem vegetal, em particular a soja, e pela divulgação de pesquisas mostrando a relação benéfica entre as dietas ricas em ácidos graxos poli-insaturados e a diminuição das doenças cardiovasculares ${ }^{4,5}$. 
Os ácidos graxos saturados, o colesterol e os carboidratos dietários promovem alterações no metabolismo lipídico tecidual e sérico, o que pode causar doenças cardiovasculares. Tanto o grau de saturação quanto o tamanho da cadeia dos ácidos graxos, bem como as suas distribuiç̧ões posicionais nas moléculas de triacilgliceróis, exercem efeitos importantes sobre a colesterolemia e os lipídeos celulares $^{6}$. Assim, o estudo teve como objetivo analisar as alterações lipídicas séricas e morfológicas hepáticas de ratos alimentados com diferentes fontes lipídicas (óleo de soja, gordura de peixe e porco, margarina e manteiga).

\section{M É T O D O S}

O experimento foi realizado com 50 ratos machos adultos da linhagem Wistar, provenientes do Biotério da Universidade Federal de Viçosa UFV (Viçosa, MG). Os animais pesavam entre 250 e $290 \mathrm{~g}$ e foram divididos aleatoriamente em cinco grupos de dez animais, mantidos em gaiolas individuais, em ambiente com fotoperíodo de 12 horas e temperatura entre 22 e $24^{\circ} \mathrm{C}$.

Foram utilizadas dietas semissintéticas, sendo sua composição baseada na formulação recomendada pelo American Institute of Nutrition AIN-93M ${ }^{7}$. Cada grupo foi alimentado com uma das dietas durante 28 dias: óleo de soja (S), gordura de porco (L), manteiga (B), margarina $(M)$ e gordura de peixe (F). O amido de milho, a sacarose, o óleo de soja, a manteiga, a margarina e a banha de porco foram adquiridos no comércio local de Viçosa e distribuídos nas dietas na quantidade de 127,3g de cada fonte lipídica estudada, de forma que todas as dietas fossem isoenergéticas, isoglicídicas, isoproteicas e isolipídicas ${ }^{6}$.

Para minimizar a oxidação lipídica, todas as dietas foram preparadas quinzenalmente e estocadas a $4^{\circ} \mathrm{C}$, até o momento da distribuição nos comedouros. Os animais receberam água destilada e dieta ad libitum. O consumo alimentar e o peso corporal dos animais foram registrados semanalmente para o cálculo do coeficiente de eficiência alimentar (CEA). O CEA foi calculado através da equação: CEA = [ganho de peso (g)] / [consumo alimentar (g)].

Para a obtenção da gordura de peixe, utilizou-se o espécime do gênero Piaractus mesopotamicus (pacu), adquirido de criação em cativeiro em Viçosa, na primeira quinzena de junho de 2002, com o peso médio de 1,5kg/animal. O tecido adiposo celomático aparente foi removido, aquecido por 5 minutos em béquer sob chama de Bunsen e, em seguida, a gordura foi filtrada em peneira plástica e armazenada em frasco âmbar sob refrigeração ${ }^{6}$.

No final do experimento, após jejum de 12 horas, os animais foram anestesiados $\mathrm{Com} \mathrm{CO}_{2}$ e, após abertura torácica e abdominal, amostras sanguíneas foram coletadas por punção cardíaca e centrifugadas $(2368,8 \times \mathrm{g})$ durante 15 minutos, para a obtenção do plasma, que foi mantido sob refrigeração por 2 horas. Uma alíquota de plasma foi utilizada para determinar as concentrações de colesterol total e de lipoproteína de alta densidade - colesterol (HDL - colesterol), e o remanescente para as análises das concentrações de albumina, triacilgliceróis e da atividade enzimática da lipase lipoproteica.

Os constituintes sanguíneos foram analisados por meio de kits de ensaio enzimático. A concentração sérica de HDL-colesterol foi determinada utilizando-se o kit da Biomerieux ${ }^{8}$ e para o colesterol total utilizou-se o kit da In Vitro Diagnóstica ${ }^{8}$, através de analisador multiparamétrico (Alizé, Mod Lisabio B.652). As concentrações de albumina ${ }^{9}$ e de triacilgliceróis ${ }^{10}$ foram determinadas por método espectrofotométrico (Biospectro, 752 UVNIS, n² 200002004), utilizando-se os kits Doles e Laborlab, respectivamente. A atividade enzimática da lipase lipoproteica foi determinada por espectrofotometria, utilizando-se o kit da Bioclin.

A análise dos tipos de ácidos graxos presentes nas fontes lipídicas estudadas foi realizada no Laboratório de Bromatologia do Departamento de Nutrição da Universidade Federal de Viçosa. Foi realizada a extração lipídica das fontes utilizadas, visando remover sujidades que viessem a 
interferir no processo de derivatização. Os extratos lipídicos foram diluídos em $5 \mathrm{~mL}$ de clorofórmio e armazenados a $-20^{\circ} \mathrm{C}$ em frascos âmbar até a etapa da derivatização (saponificação, seguida de acidificação e esterificação) dos ácidos graxos. As amostras esterificadas foram concentradas com nitrogênio gasoso, diluídas em $1 \mathrm{~mL}$ de hexano e analisadas por cromatografia gasosa ${ }^{6}$.

Foi injetada uma alíquota de $1 \mu \mathrm{L}$ no cromatógrafo a gás CG-17A Shimadzu/Class, equipado com uma coluna capilar de sílica fundida SP-2560 (biscianopropil polysiloxane) de 100m e $0,25 \mathrm{~mm}$ de diâmetro interno, e razão split (divisão de fluxo) de 1:75, usando o nitrogênio como gás de arraste a uma velocidade linear de $14,48 \mathrm{~cm} / \mathrm{seg}$. A temperatura inicial era de $100^{\circ} \mathrm{C}$, seguida de temperatura programada em três etapas: a primeira de $10^{\circ} \mathrm{C} / \mathrm{min}$ até $180^{\circ} \mathrm{C}$, a segunda de $1^{\circ} \mathrm{C} /$ min até $240^{\circ} \mathrm{C}$ e a terceira de $240^{\circ} \mathrm{C}$ mantidos por 10 minutos. As temperaturas do injetor e do detector de ionização de chama foram mantidas a 250 e $260^{\circ} \mathrm{C}$, respectivamente. Os picos foram identificados por comparação dos tempos de retenção com padrões de metil ésteres conhecidos (SIGMA Chemical Co, n 189-19). Os resultados foram expressos como percentual da concentração relativa (100mg de lipídeo/1 $\mathrm{mL}$ de hexano).

As amostras do fígado e coração foram lavadas com solução salina $(0,9 \%)$, pesadas e fixadas em formaldeído 10\% tamponado durante $24 \mathrm{~h}$ para as análises histológicas. Posteriormente elas foram mantidas em álcool $70 \%$ até o momento da inclusão em parafina. Foi realizado um corte transversal na região átrio-ventricular para análise da porção inicial da aorta e das coronárias, uma vez que os processos degenerativos são mais acentuados nessa região. Os cortes de $4 \mu \mathrm{m}$ em micrótomo rotativo (Reichert-jung 2045 Multicut, Germany) foram corados por Hematoxilina-Eosina (H\&E) e analisados sob microscopia de luz (Olympus BX 41) para uma análise qualitativa quanto à histologia desses tecidos (hepatócitos, parede das coronárias e capilares cardíacos). A classificação qualitativa quanto ao teor de lipídeos hepáticos foi expressa em cruzes ( 0 a $3+$ ), obtida através da média de três campos microscópicos aleatórios de cada animal/grupo, sendo avaliados em aumento de 20X e Zoom de 2,0, considerando-se a seguinte graduação:

0+: ausência de gotas lipídicas no citoplasma hepático;

$1+$ : presença de gotas lipídicas no citoplasma hepático de intensidade leve (menos de 25\% do campo analisado);

$2+$ : presença de gotas lipídicas no citoplasma hepático de intensidade moderada (25 a 50\% do campo analisado);

$3+$ : presença de gotas lipídicas no citoplasma hepático de intensidade alta (mais de 50\% do campo analisado).

Todos os procedimentos realizados com os animais respeitaram os princípios éticos contidos na Declaração de Helsinki (2000) ${ }^{11}$, além do atendimento às legislações específicas do país no qual a pesquisa foi realizada.

Os valores foram representados como Média (M) e Desvio-Padrão (DP). A Análise de Variância (ANOVA), seguida pelo teste de Tukey, foi realizada para verificar se havia diferença significativa $(p<0,01$ e $p<0,05)$ entre os grupos.

\section{RESULTADOS}

O perfil em ácidos graxos de cada fonte lipídica estudada encontra-se na Tabela 1. A margarina apresentou um perfil de ácidos graxos semelhante ao seu precursor, o óleo de soja. Este apresenta um alto teor de ácidos graxos insaturados, sendo esta a sua principal diferença em relação à margarina. De outra parte, devem ser destacados os teores de ácidos graxos trans presentes na margarina, diferenciando-a das demais fontes. As gorduras de porco e peixe assemeIharam-se entre si, nas relações entre ácidos graxos insaturados e saturados.

As fontes lipídicas analisadas não promoveram diferenças estatísticas significativas quanto o ganho de peso total, o consumo alimentar total e o coeficiente de eficiência alimentar (Tabela 2). 
Tabela 1. Composição de ácidos graxos presentes nas diferentes fontes lipídicas (g/100g dos ácidos graxos totais). Viçosa (MG), 2002.

\begin{tabular}{|c|c|c|c|c|c|}
\hline Ácidos graxos & Óleo de soja (S) & Gordura de porco $(\mathrm{L})$ & Manteiga (B) & Margarina (M) & Gordura de peixe (F) \\
\hline $10: 0$ & - & - & 3,8 & - & - \\
\hline $12: 0$ & - & - & 4,2 & - & - \\
\hline $14: 0$ & - & 1,0 & 12,3 & - & 1,3 \\
\hline 16:0 & 9,9 & 30,0 & 43,7 & 15,5 & 23,7 \\
\hline $17: 0$ & - & 0,5 & - & - & 0,6 \\
\hline 18:0 & 3,6 & 13,1 & 11,2 & 11,3 & 12,2 \\
\hline $20: 0$ & 0,4 & 0,2 & - & 0,5 & 0,2 \\
\hline $21: 0$ & - & - & - & - & 0,2 \\
\hline $22: 0$ & 0,4 & - & - & 0,5 & - \\
\hline $23: 0$ & - & 0,2 & - & - & 0,5 \\
\hline$\sum(\mathrm{SFA})$ & 14,3 & 45,0 & 75,0 & 27,8 & 38,7 \\
\hline $14: 1$ & - & - & 2,7 & - & 0,4 \\
\hline $16: 1$ & - & 2,0 & 1,4 & - & 6,0 \\
\hline $17: 1$ & - & 0,3 & - & - & 0,3 \\
\hline $18: 1$ & 21,8 & 37,1 & 19,1 & 22,8 & 41,2 \\
\hline $20: 1$ & 0,5 & 0,6 & - & 0,4 & 0,9 \\
\hline$\Sigma$ (MUFA) & 22,3 & 40,0 & 23,2 & 23,2 & 48,8 \\
\hline $18: 1 \mathrm{t}$ & - & 0,2 & - & 17,3 & 1,0 \\
\hline $18: 2 \mathrm{t}$ & 0,2 & - & - & 1,3 & - \\
\hline$\sum$ Trans & 0,2 & 0,2 & - & 18,6 & 1,0 \\
\hline $18: 2(n-6)$ & 56,8 & 13,7 & 1,5 & 27,8 & 10,3 \\
\hline $18: 3(n-6)$ & 0,4 & - & - & 0,5 & - \\
\hline $18: 3(n-3)$ & 6,0 & 0,5 & - & 2,0 & 0,5 \\
\hline $20: 2$ & - & 0,5 & - & - & 0,4 \\
\hline $20: 3$ & - & - & - & - & 0,5 \\
\hline$\sum$ (PUFA) & 63,2 & 14,7 & 1,5 & 30,3 & 11,7 \\
\hline
\end{tabular}

-: ácidos graxos não detectados; SFA: ácidos graxos saturados; Trans: ácidos graxos trans; MUFA: ácidos graxos monoinsaturados; PUFA: ácidos graxos poli-insaturados.

Tabela 2. Valores médios e desvio padrão de ganho de peso total, consumo alimentar total e coeficiente de eficiência alimentar de ratos alimentados com diferentes fontes lipídicas. Viçosa (MG), 2002.

\begin{tabular}{|c|c|c|c|c|c|c|c|c|c|c|}
\hline \multirow{3}{*}{ Variáveis } & \multicolumn{10}{|c|}{ Grupos } \\
\hline & \multicolumn{2}{|c|}{$S$} & \multicolumn{2}{|c|}{$B$} & \multicolumn{2}{|c|}{$\mathrm{M}$} & \multicolumn{2}{|c|}{$\mathrm{L}$} & \multicolumn{2}{|c|}{$F$} \\
\hline & M & DP & $M$ & DP & M & DP & $M$ & DP & M & DP \\
\hline CAT (g) & 530,00 & 34,20 & 516,90 & 43,80 & 537,90 & 41,90 & 507,40 & 40,20 & 538,50 & 31,10 \\
\hline CEA & 0,15 & 0,01 & 0,15 & 0,03 & 0,15 & 0,02 & 0,14 & 0,02 & 0,15 & 0,02 \\
\hline
\end{tabular}

GPT: ganho de peso total; CAT: consumo alimentar total; CEA: coeficiente de eficiência alimentar. S: óleo de soja; L: gordura de porco; B: manteiga; M: margarina; F: gordura de peixe; M: média; DP: desvio-padrão.

Os valores de média e desvio-padrão foram feitos com base na amostra de dez animais/grupo. Ausência de letras nas linhas não diferem ( $p<0,01$ e $p<0,05)$ pelo teste de Tukey.

Quanto à análise da trigliceridemia, o grupo alimentado com óleo de soja diferiu estatisticamente dos grupos alimentados com gordura de porco (L), margarina $(\mathrm{M})$ e gordura de peixe (F) (Tabela 3).
O grupo L apresentou maior concentração de colesterol total que o grupo $S(p<0,01)$ e maior concentração de colesterol total quando comparado aos grupos $\mathrm{S}$ e $\mathrm{M}(p<0,05)$. O grupo alimentado com gordura de porco (grupo L) apresentou- 
148 | M.E.F. ALMEIDA et al.

Tabela 3. Concentrações de lipídeos plasmáticos em ratos alimentados com diferentes fontes lipídicas. Viçosa (MG), 2002.

\begin{tabular}{|c|c|c|c|c|c|c|c|c|}
\hline \multirow{3}{*}{ Grupos } & \multicolumn{8}{|c|}{ Lipídeos plasmáticos } \\
\hline & \multicolumn{2}{|c|}{ Triacilgliceróis (mg/dL) } & \multicolumn{2}{|c|}{ Colesterol total (mg/dL) } & \multicolumn{2}{|c|}{ HDL-Colesterol (mg/dL) } & \multicolumn{2}{|c|}{ Colesterol total/HDL-colestero } \\
\hline & $\mathrm{M}$ & DP & M & $\mathrm{DP}$ & M & DP & M & $\mathrm{DP}$ \\
\hline$S$ & 74,7 & $16,6^{\mathrm{a}}$ & 72,2 & $6,2^{\mathrm{a}^{*}}$ & 51,0 & $4,0^{a^{*}}$ & 1,4 & $0,1^{a^{*}}$ \\
\hline L & 134,2 & $24,1^{\mathbf{b}}$ & 89,8 & $7,3^{b^{\star *}}$ & 49,3 & $7,2^{\mathrm{a}}$ & 1,9 & $0,3^{\mathrm{a}^{* *}}$ \\
\hline B & 117,2 & $32,9^{a, b}$ & 82,1 & $14,2^{a, b}$ & 42,4 & $3,6^{\mathrm{a}}$ & 1,9 & $0,2^{a^{\star *}}$ \\
\hline$M$ & 133,0 & $45,7^{\mathbf{b}}$ & 76,4 & $7,5^{a, b^{*}}$ & 41,3 & $10,7^{a^{* *}}$ & 2,0 & $0,7^{a^{\star *}}$ \\
\hline $\mathrm{F}$ & 157,5 & $54,7^{\mathbf{b}}$ & 82,1 & $7,8^{a, b}$ & 49,5 & $6,9^{a}$ & 1,7 & $0,2^{\mathrm{a}}$ \\
\hline
\end{tabular}

S: óleo de soja; L: gordura de porco; B: manteiga; M: margarina; F: gordura de peixe.

Os valores de Média (M) e Desvio-Padrão (DP) foram feitos com base na amostra de dez animais/grupo. Mesmas letras na coluna não diferem $(p<0,01)$, e símbolos (asteriscos) diferentes na coluna diferem $(p<0,05)$ pelo teste de Tukey.

Tabela 4. Concentração plasmática de albumina ( $\mathrm{g} / \mathrm{dl}$ ) e atividade enzimática da lipase lipoproteica (UI) de ratos alimentados com diferentes fontes lipídicas. Viçosa (MG), 2002.

\begin{tabular}{lccccc}
\hline \multirow{2}{*}{ Grupos } & \multicolumn{2}{c}{ Albumina } & & \multicolumn{2}{c}{ Lipase lipoproteica } \\
\cline { 2 - 3 } \cline { 5 - 6 } & $M$ & DP & & M & DP \\
\hline S & 4,87 & $0,88^{\mathbf{a}}$ & & 10,86 & $5,17^{\mathbf{a}}$ \\
$\mathrm{L}$ & 3,77 & $0,32^{\mathbf{b}}$ & & 12,23 & $5,85^{\mathbf{a}}$ \\
$\mathrm{B}$ & 3,89 & $0,72^{\mathbf{b}}$ & & 8,86 & $6,26^{\mathbf{a}}$ \\
$\mathrm{M}$ & 3,36 & $0,19^{\mathbf{b}}$ & & 8,15 & $4,10^{\mathbf{a}}$ \\
$\mathrm{F}$ & 3,55 & $0,36^{\mathbf{b}}$ & & 7,18 & $3,11^{\mathbf{a}}$ \\
\hline
\end{tabular}

S: óleo de soja; L: gordura de porco; B: manteiga; M: margarina; F: gordura de peixe. Os valores de média e desvio-padrão foram feitos com base na amostra de dez animais/grupo.

Mesmas letras na coluna não diferem pelo teste de Tukey $(p<0,05)$.

-se diferente estatisticamente $(p<0,05)$ dos grupos alimentados com óleo de soja e margarina. Somente os grupos S e M diferiram estatisticamente quanto ao $\mathrm{HDL}$-colesterol $(p<0,05)$, sendo que este último apresentou uma concentração menor desse tipo de lipoproteína quando comparado com o primeiro grupo. Ao analisar a razão de colesterol total/HDL-colesterol (Tabela 3) observa-se que o grupo $S$ diferiu $(p<0,05)$ dos grupos $L, B$ e $M$, que foram iguais entre si.

O perfil de ácidos graxos das fontes lipídicas não demonstrou influenciar a atividade enzimática da lipase lipoproteica (Tabela 4), mas o grupo alimentado com óleo de soja apresentou uma maior concentração plasmática da albumina.

Comparando os grupos S, L, M e F, que diferiram quanto à concentração de triacilgliceróis, observa-se que o grupo S apresentou menor concentração sérica dessa molécula e também maior concentração de albumina.

Não foi observada diferença significativa quanto ao peso do fígado, mas, pela análise qualitativa da histologia hepática (Figura 1), observou-se uma deposição lipídica característica de esteatose nos grupos S, B, L e F. Pela análise histológica da aorta foi constatado que as diferentes fontes lipídicas não alteraram a morfologia do endotélio e das túnicas íntima e média dessa artéria. Foram observadas gotículas lipídicas na parede das coronárias e de capilares de todos os grupos.

\section{I S C U S S Ã O}

Não houve diferença estatística no ganho de peso, consumo alimentar e consequentemente no coeficiente de eficiência alimentar. O coeficiente de eficiência alimentar é uma importante ferramenta para avaliar a ingestão de nutrientes e sua absorção pelos tecidos. No estudo de Suzuky et al. ${ }^{12}$, os animais alimentados com dietas à base de óleo de soja e gordura de porco apresentaram maior consumo alimentar quando comparados aos outros grupos, enquanto no estudo de Rolland et al..$^{13}$ os animais alimentados com manteiga apresentaram maior consumo alimentar quando comparados com aqueles que receberam óleo de soja. 


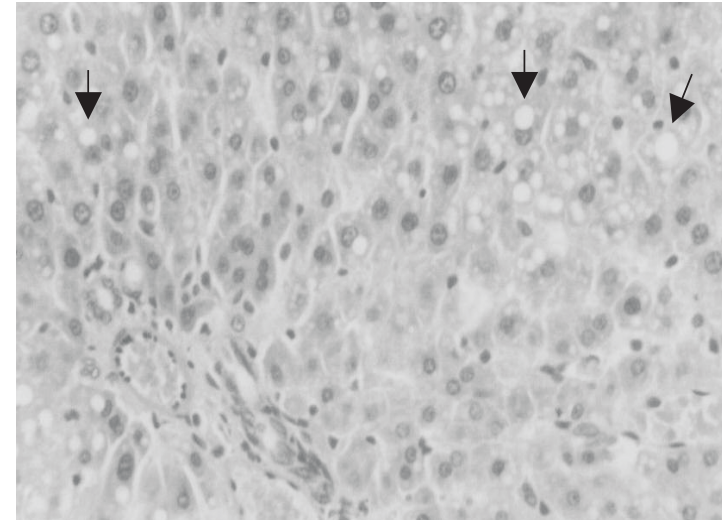

$\mathbf{S}$

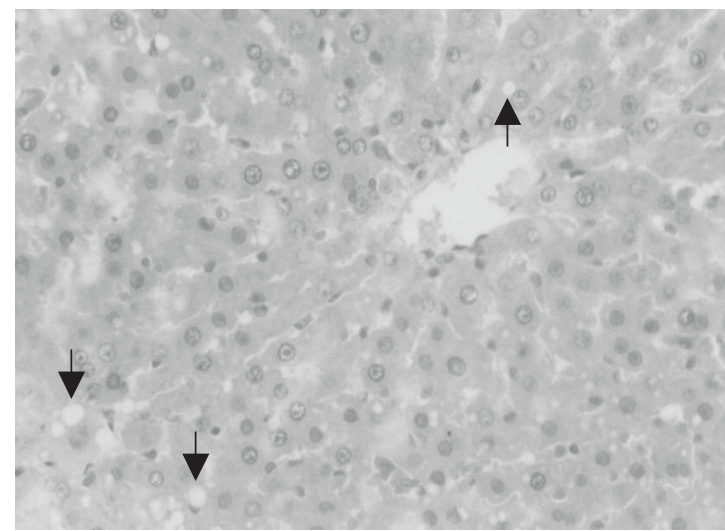

B

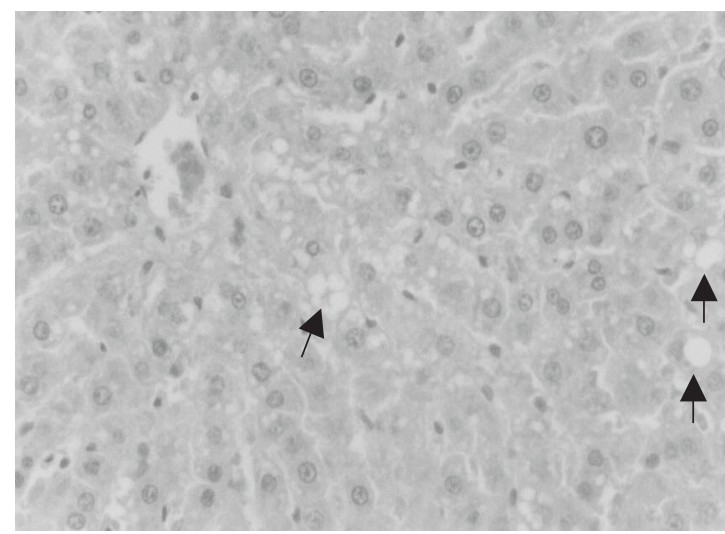

F

A trigliceridemia sofre redução significativa quando modelos animais alimentados com fontes lipídicas ricas em ácidos graxos poli-insaturados, tais como óleos de oliva e de milho, são comparados com aqueles que recebem fontes ricas em ácidos graxos saturados, como gorduras de porco

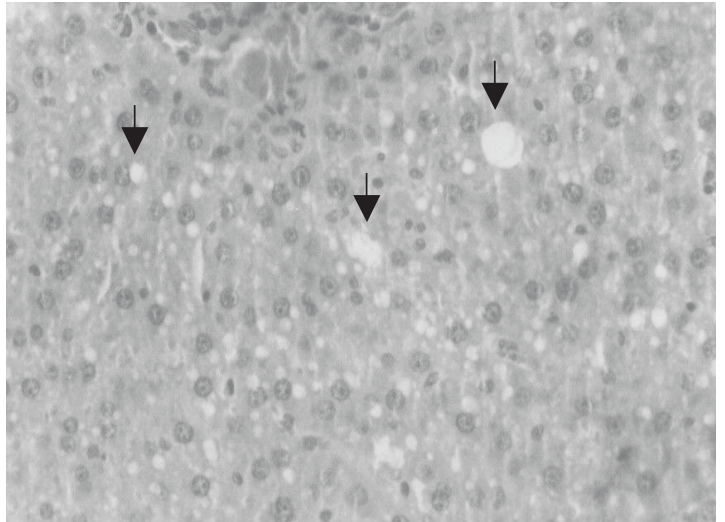

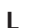

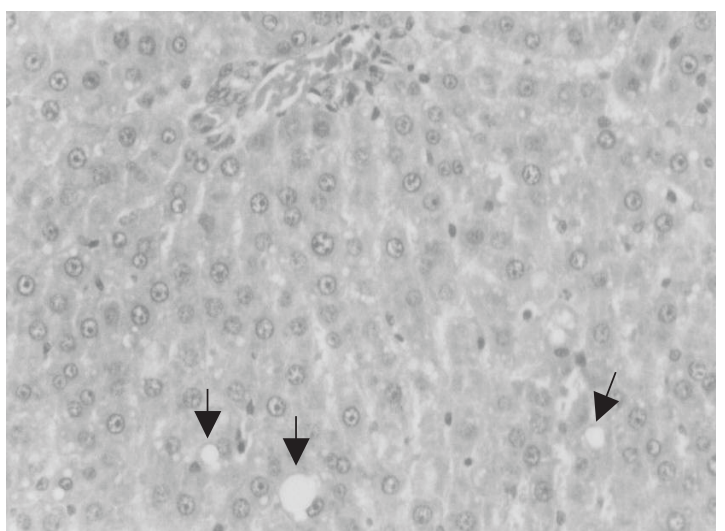

M

Figura 1. Parênquima hepático de ratos Wistar alimentados com diferentes fontes lipídicas indicando a presença de lipídeos. Coloração (H\&E), aumento 20X, Zoom 2,0. Viçosa (MG), 2002.

Nota: S: óleo de soja; L: gordura de porco; B: manteiga; M: margarina; F: gordura de peixe.

Classificação qualitativa do teor lipídico: $1+$ intensidade leve (M); $2+$ intensidade moderada (B, F); $3+$ intensidade alta $(S, L)$.

e de $\operatorname{coco}^{14,15}$. Lai \& Ney ${ }^{16}$, ao observarem os efeitos do óleo de milho, gordura de palma e manteiga (líquida e sólida) sobre os lipídeos séricos, verificaram que a manteiga líquida não diferia do óleo de milho para os triacilgliceróis plasmáticos, e que a manteiga sólida apresentava efeito seme- 
Ihante à gordura de palma. Foi também observado que a concentração de triacilglicerol hepático era maior na fonte lipídica da gordura de palma, cujos ácidos graxos são predominantemente saturados.

Segundo Garg \& Blake17, o ácido graxo linoleico apresenta efeito hipocolesterolemiante, podendo sugerir que a menor concentração de colesterol apresentada no grupo $S$, quando comparado ao grupo $L(p<0,01)$, pode ser uma consequência do efeito desse tipo de ácido graxo. Em ratos, a concentração de HDL-colesterol apresenta valores superiores quando comparadas às de $\mathrm{LDL}^{-}$-colesterol ${ }^{18}$. Segundo Almeida ${ }^{18}$, a presença de ácidos graxos trans em alimentos pode diminuir a concentração de HDL-colesterol, fato sugerido para justificar a menor concentração de HDL-colesterol presente no grupo $\mathrm{M}$, quando comparado o grupo $S(p<0,05)$.

Um indicador do risco de doenças cardiovasculares é a razão colesterol total/HDL-colesterol. Uma redução de 0,01 nesse parâmetro reduz o risco de infarto do miocárdio em aproximadamente $0,5 \%{ }^{19}$. Somente os grupos $\mathrm{S}, \mathrm{L}, \mathrm{B}$ e $\mathrm{M}$ diferiram quanto a essa razão $(p<0,05)$, sendo considerado como melhor valor aquele apresentado pelo grupo S. O grupo M apresentou menor concentração de $\mathrm{HDL}$-colesterol $(p<0,05)$ quando comparado com o grupo $S$, podendo-se atribuir esse resultado à elevada concentração de ácidos graxos trans presentes na margarina, os quais podem ser mais potentes que os ácidos graxos saturados, na elevação da concentração sérica de LDL-colesterol e na diminuição de HDL-colestero| ${ }^{20}$.

A albumina e a lipase lipoproteica são duas proteínas importantes no metabolismo lipídico, pois uma alta concentração da albumina expressa um maior transporte de ácidos graxos livres no plasma ${ }^{21}$, enquanto uma elevada atividade enzimática da lipase lipoproteica poderá ser um indicativo de maior captação dos ácidos graxos pelos tecidos, visto que esta enzima promove a hidrólise capilar dos triacilgliceróis e, assim, permite a endocitose celular.

Sugere-se que a menor concentração de triacilgliceróis e a maior concentração de albumina apresentada pelo grupo $S$, quando comparada aos grupos L, M e F, seja resultante da maior distribuição dos triacilgliceróis pela albumina e maior captação dos ácidos graxos pelos tecidos.

A atividade enzimática da lipase lipoproteica tem demonstrado ser maior para os animais que recebem fontes alimentares ricas em ácidos graxos insaturados, principalmente da série $\varpi 3^{16,22,23}$. Entretanto, não foi observada diferença significativa quanto à atividade sérica desta enzima quando comparado o grupo que apresentou a maior concentração de ácido linolênico (grupo S) com os demais grupos.

A esteatose hepática é caracterizada por um acúmulo de partículas de VLDL, fazendo com que o fígado apresente um peso $5 \%$ maior que o valor de referência ${ }^{24}$, sendo essa característica uma resultante direta do tipo de fonte lipídica utilizada ${ }^{16,25}$.

A ausência de alterações na morfologia do endotélio e das túnicas íntima e média da aorta dos animais estudados pode ser devida ao fato se que esse modelo animal apresenta-se resistente à aterosclerose, em razão da baixa atividade da enzima Cholesteryl Ester Transfer Protein (CETP), da elevada atividade da enzima regulatória da via de síntese dos sais biliares e dos elevados níveis de HDL-colesterol apresentados ${ }^{26-28}$. Entretanto, a presença de gotículas lipídicas na parede das coronárias e dos capilares de todos os grupos avaliados, demonstra a necessidade de outros estudos para verificar se elas foram acumuladas ao longo do tempo e se conduzirão a processos patológicos, ou se foram oriundas da própria síntese vascular. Nielsen et al. ${ }^{29}$ sugerem que a secreção de lipoproteínas pelo coração pode representar um caminho de transporte reverso dos triacilgliceróis, pelo qual os miócitos podem descarregar o excesso de moléculas lipídicas (ácidos graxos livres e triacilgliceróis) não utilizadas como combustível e que poderão exercer efeitos lipotóxicos. Assim, a elevada concentração de lipídeos séricos, juntamente com aqueles presentes no endotélio vascular cardíaco, pode contribuir ou até mesmo agravar a formação das placas ateromatosas. 


\section{O N CLUS Ã O}

A fonte lipídica que apresentou os melhores resultados foi o óleo de soja. O consumo de gordura do peixe causou efeito sérico e tecidual semelhante ao encontrado nas outras fontes lipídicas (gordura de porco, manteiga e margarina), as quais podem contribuir para o surgimento e a progressão das doenças cardiovasculares.

\section{A GRADECIMENTOS}

Aos colegas de laboratórios e aos professores de todos os departamentos citados, que ajudaram na obtenção e análise dos dados, bem como à Coordenação de Aperfeiçoamento de Pessoal de Nível Superior, pelo suporte financeiro.

\section{COLABORADORES}

M.E.F. ALMEIDA participou de todas as etapas do planejamento a elaboração do artigo. J.H. QUEIROZ participou do planejamento, da execução e da supervisão do projeto de pesquisa, bem como da redação do artigo. N.M.B. COSTA participou da coleta dos dados, bem como da discussão dos resultados. S.L.P. MATTA participou da coleta dos dados.

\section{REFERÊ N CIAS}

1. Teitelbaum JE, Walker WA. Review: the role of omega 3 fatty acids in intestinal inflammation. J Nutr Biochem. 2001; 12(1):21-32. doi: 10.1016/s0 955-2863(00)00141-8.

2. Bang HO, Dyerberg J, Sinclair HM. The composition of the Eskimo food in north western Greenland. Am J Clin Nutr. 1980; 33(12):2657-61.

3. Maia EL, Rodrigues-Amaya DB, Hotta LK. Fatty acid composition of the total, neutral and phospholipids of pond-raised Brazilian Piaractus mesopotamicus. Int J Food Sci Technol. 1995; 30(5):591-7. doi: 10.1111/j.1365-2621.1995.tb01407.x.

4. Mondini L, Monteiro CA. Mudanças no padrão de alimentação da população urbana brasileira (19621988). Rev Saúde Pública. 1994; 28(6):433-9. doi: 10.1590/S0034-89101994000600007.

5. Monteiro CA, Mondini L, Costa RBL. Mudanças na composição e adequação nutricional da dieta familiar nas áreas metropolitanas do Brasil (19881996). Rev Saúde Pública. 2000; 34(3):251-8. doi: 10.1590/S0034-89102000000300007.

6. Almeida MEF, Queiroz JH, Queiroz MELR, Costa NMB, Matta SLP. Perfil lipídico tecidual de ratos alimentados com diferentes fontes lipídicas. Rev Nutr. 2009; 22(1):51-60. doi: 10.1590/S1415-52 732009000100005.

7. Reeves PG. Components of the AIN-93 diets as improvements in the AIN-76A diet. J Nutr. 1997; 127(Suppl 5):838S-41S

8. Allain CC, Poon LS, Chan CS, Richmond W, Fu PC. Enzymatic determination of total cholesterol. Clin Chem. 1974; 20(4):470-5.

9. Pinnell $A E$, Northam BE. New automated dye-binding method for serum albumin determination with bromocresol purple. Clin Chem. 1978; 24(1):80-6.

10. Bucolo G, David H. Quantitative determination of serum triglycerides by the use of enzymes. Clin Chem. 1973; 19(5):476-82.

11. Declaração de Helsinki [acesso em 2009 jan 23]. Disponível em: <http://www.ufrgs.br/bioetica/ helsin6.htm>.

12. Suzuky H, Hayakawa S, Tamura S, Wada S, Wada O. Effect of age on the modification of rat plasma lipids by fish and soybean oil diets. Biochim Biophys Acta. 1985; 836(3):390-6.

13. Rolland V, Roseau S, Fromentin G, Nicolaidis S, Tomé D, Even PC. Body weight, body composition, and energy metabolism in lean and obese Zucker rats fed soybean oil or butter. Am J Clin Nutr. 2002; 75(1):21-30.

14. Nielsen LB, Leth-Espensen P, Nordestgaard BG, Foged E, Kjeldsen K, Stender S. Replacement of dietary saturated fat with monounsaturated fat: effect on atherogenesis in cholesterol-fed rabbits clamped at the same plasma cholesterol level. $\mathrm{Br} J$ Nutr. 1995; 74(4):509-21.

15. Chen HW, Lii CK, Ou CC, Wang ML. Dietary fat and vitamin $E$ have differential effects on serum lipid levels. Nutr Res. 1995; 15(9):1367-76. doi: 10.1016/0271-5317(95)02011-J.

16. Lai H-C, Ney DM. Corn oil, palm oil and butterfat fractions affect postprandial lipemia and lipoprotein lipase in meal-fed rats. J Nutr. 1995; 125(6):1536-45.

17. Garg ML, Blake R. Cholesterol dynamics in rats fed diets containing either canola oil or sunflower oil. Nutr Res. 1997; 17(3):485-92. doi: 10.1016/S0271-5 317(97)00009-2.

18. Almeida MEF. Perfil lipídico e morfologia hepática, aórtica e cardíaca de ratos alimentados com diferentes fontes lipídicas [dissertação]. Viçosa: Universidade Federal de Viçosa; 2003. 
152 | M.E.F. ALMEIDA et al.

19. Stampfer MJ, Sacks FM, Salvani S, Willett WC, Henneckens $\mathrm{CH}$. A prospective study of cholesterol, apoliproteins, and the risk of myocardial infarction. N Engl J Med. 1991; 325(6):373-81.

20. Kubow S. The influence of positional distribution of fatty acids in native, interesterified and structurespecific lipids on lipoprotein metabolism and atherogenesis. J Nutr Biochem. 1996; 7(10):530-41. doi: 10.1016/S0955-2863(96)00106-4.

21. Nassir F, Zimowska W, Bayle D, Gueux E, Rayssiguier $Y$, Mazur A. Hypoalbuminaemia in acute phase is not related to depressed albumin synthesis: experimental evidence in magnesium-deficient rat. Nutr Res. 2002; 22(4):489-96. doi: 10.1016/S0271-5 317(01)00399-2.

22. Lombardo YB, Chicco A, D’Alessandro ME, Martinelli M, Soria A, Gutman R. Dietary fish oil normalize dyslipidemia and glucose intolerance with unchanged insulin levels in rats fed a high sucrose diet. Biochem Biophys Acta. 1996; 1299(2):175-82. doi: 10.1016/0005-2760(95)00 $197-2$

23. Perona JS, Ruiz-Gutiérrez V. Two highly monounsaturated oils, olive oil and high-oleic sunflower oil, induce diferent triacylglycerol molecular species distribution in rat liver. Nutr Res. 1998; 18(10):1723-32. doi: 10.1016/S0271-5317 (98)00144-4.

24. Leclercq I, Horsmans Y, Desager J-P, Delzenne N, Geubel AP. Reduction in hepatic cytochrome P-450 is correlated to the degree of liver fat content in animal models of steatosis in the absence of inflammation. J Hepatol. 1998; 28(3):410-6. doi: 10.1016/S0168-8278(98)80314-0.

25. Monsma CC, Gallaher DD, Ney DM. Reduced digestibility of beef tallow and cocoa butter affects bile acid excretion and reduces hepatic esterified cholesterol in rats. J Nutr. 1996; 126(8):2028-35.

26. Fernandez ML, McNamara DJ. Characterization of high-density lipoprotein binding to guinea pig hepatic membranes: effects of dietary fat quality and cholesterol feeding. Metabolism. 1991; 40(2): 127-34. doi: 10.1016/0026-0495(91)90162-P.

27. Yamashita S, Maruyama T, Hirano K-I, Sakai N, Nakajina N, Matsuzawa Y. Molecular mechanisms, lipoprotein abnormalities and atherogenicity of hyperalphalipoproteinemia. Atherosclerosis. 2000; 152(2):271-85. doi: 10.1016/S0021-9150(00)005 74-8.

28. Moghadasian MH. Experimental atherosclerosis. a historical overview. Life Sci. 2002; 70(8):855-65. doi: 10.1016/S0024-3205(01)01479-5.

29. Nielsen LB, Véniant M, Borén J, Raabe M, Wong JS, Tam C, et al. Genes for apolipoprotein B and microsomal triglyceride transfer protein are expressed in the heart. Circulation. 1998; 98(1):13-6.

Recebido em: 28/4/2009

Versão final reapresentada em: 22/2/2010 Aprovado em: 12/8/2010 